\title{
Safety, Pharmacokinetic, and Pharmacodynamic Study of a Sublingual Formula for the Treatment of Vasovagal Syncope
}

\author{
Paul Hutson ${ }^{1}$ (1) $\cdot$ Regis Guieu ${ }^{2,3} \cdot$ Jean-Claude Deharo ${ }^{2,3} \cdot$ Pierre Michelet $^{2,3} \cdot$ Michele Brignole $^{4}$. \\ Cassondra Vander Ark $^{5} \cdot$ Mohamed H. Hamdan ${ }^{5}$
}

Accepted: 20 December 2021 / Published online: 12 February 2022

(c) The Author(s) 2022

\begin{abstract}
Background Vasovagal syncope is a common cause of syncope which, if recurrent, can have multiple negative consequences such as injury and occupational disability. Various medications can be used to decrease the recurrence of vasovagal syncope but there are no drugs that can be used by patients to interrupt a perceived vasovagal episode.

Methods A phase I study was performed to evaluate the tolerability and safety of a gel formulation containing capsaicin $(1 \mathrm{mg})$, phenylephrine HCL (PE) and caffeine citrate (200 mg) (CPC) in normal adult volunteers. Secondary objectives were to characterize the pharmacokinetics (PK) of the CPC formulation and the highest dose of PE needed to achieve a target increase in systolic BP of at least $40 \mathrm{mmHg}$. After receiving the first dose, a second dose of the CPC mixture was administered at $2 \mathrm{~h}$. Suboptimal changes in systolic blood pressure (SBP) were noted at PE doses of 0.6, 1.2, and $1.8 \mathrm{mg}$, therefore a second cohort was studied at PE doses of 10, 20, and $30 \mathrm{mg}$. Blood samples were collected in rapid sequence and were assayed for all three drugs.

Results A total of 17 subjects received the drug with no serious adverse effects reported. All doses were well tolerated, although the capsaicin content usually caused expected temporary oral and gastric discomfort. One subject did not complete the study because of a vasovagal reaction that was associated with the frequent blood sampling. There was a 5-25 min lag in the appearance of measurable blood concentrations of capsaicin and phenylephrine. Most subjects had baseline caffeine concentrations from dietary use, with a gradual increase noted after 15 min consistent with GI absorption. Although the intended criterion of a $40 \mathrm{mmHg}$ increase in SBP was not reached, a clinically significant increase in BP for at least $15 \mathrm{~min}$ was noted in the six subjects who received the highest dose of PE $(30 \mathrm{mg})$, with a gradual decline over the next $2 \mathrm{~h}$.

Conclusion The ternary mixture of capsaicin, phenylephrine, and caffeine was well tolerated when administered as two sublingual/oral doses over a 2-h period.
\end{abstract}

Paul Hutson

paul.hutson@wisc.edu

1 School of Pharmacy, University of Wisconsin-Madison, 777 Highland Avenue, Madison, WI 53705, USA

2 Assistance Publique, Hôpitaux de Marseille, Centre Hospitalier Universitaire La Timone, Service de Cardiologie, Marseille, France

3 Aix Marseille Université, C2VN, Marseille, France

4 IRCCS, Istituto Auxologico Italiano, Faint and Fall Programme, Cardiology Unit and Department of Cardiovascular, Neural and Metabolic Sciences, S. Luca Hospital, Milan, Italy

5 Division of Cardiovascular Medicine, Department of Medicine, School of Medicine and Public Health, University of Wisconsin-Madison, 600 Highland Avenue, Madison, WI 53792, USA

\section{Key Points}

A gel containing capsaicin, phenylephrine, and caffeine (CPC) was well tolerated.

The CPC mixture, first held under the tongue and then swallowed, resulted in a modest increase in blood pressure. 


\section{Introduction}

Syncope is defined as transient loss of consciousness associated with an inability to maintain postural tone with rapid and spontaneous recovery [1]. The presumed cause is cerebral hypoperfusion. Vasovagal syncope (VVS) is the most common type of syncope affecting up to $42 \%$ of women and $32 \%$ of men by the age of 60 years $[2,3]$. It usually occurs after prolonged standing or exposure to emotional stress or pain, and is associated with features such as diaphoresis, warmth, nausea, and pallor. While the outcome in patients with VVS is usually benign, the 1-year recurrence rate is 25-35\%, risking significant impairment in quality of life, including injuries and loss of employment [4].

Several drugs are indicated in the treatment of VVS, however to our knowledge there is no available treatment of an impending syncopal attack. The primary objective of this study was to characterize the tolerability and safety of a formulation of capsaicin, phenylephrine (PE) and caffeine (CPC) in normal adult volunteers. Secondary objectives were to characterize the pharmacokinetics (PK) of the CPC formulation and the highest dose of PE needed to achieve a target increase in systolic BP of at least $40 \mathrm{mmHg}$ when combined with capsaicin and caffeine within $15 \mathrm{~min}$ of drug administration in five of six subjects.

\section{Methods}

This was an open-label, phase I, dose escalation, PK study of a novel gel formulation of capsaicin, PE, and caffeine administered sublingually to normal, healthy adults. The protocol was approved by the University of Wisconsin-Madison Human Subjects Committee, and the investigational product was provided an investigational new drug (IND) exemption by the US FDA (140732).

\subsection{Subjects}

Healthy, non-smoking adult subjects aged $18-50$ years were recruited through postings in the medical center complex. Subjects were contacted by the study coordinators for an initial screening for eligibility. Eligibility screening occurred after obtaining written informed consent. During the in-person screening visit a physical examination, 12-lead ECG, blood samples for blood chemistries, CBC with differential and platelet count, and a urine sample for drug and pregnancy testing were obtained. Women able to bear children were required to practice at least two forms of contraception during and for 7 days after the treatment day and were required to have a negative pregnancy test on the morning of treatment. Subjects were also required to refrain from taking any of the components of the investigational product in their diet for $12 \mathrm{~h}$ before and $24 \mathrm{~h}$ after the study dose. A clinically unremarkable 12-lead ECG and laboratory panel was required in screening prior to the study date, and systolic (SBP) and diastolic blood pressure (DBP) at screening were required to be $\leq 130 \mathrm{mmHg}$ and $\leq 80 \mathrm{mmHg}$, respectively. Subjects were allowed to continue taking concurrent medications that did not conflict with the eligibility requirements of the study. Concurrent medications taken within $48 \mathrm{~h}$ of the study doses were recorded.

\subsection{Investigational Drug Product}

The investigational drug product was a proprietary combination of capsaicin, PE, and caffeine in a gel base. The mixture was developed and qualified by the Zeeh Pharmaceutical Research Station located at the University of Wisconsin-Madison School of Pharmacy.

Of the three active components of CPC, the PE dose was the most uncertain and was thus the focus of dose escalation. The amount of capsaicin and caffeine in each $1 \mathrm{~mL}$ dose was held constant at $1 \mathrm{mg}$ and $200 \mathrm{mg}$, respectively. The amount of PE was increased in a modified Fibonacci escalation to identify the dose that yielded an increase in SBP of at least $40 \mathrm{mmHg}$ above baseline, yet did not exceed a SBP of $190 \mathrm{mmHg}$ or greater. An initial sequence of PE doses of $0,0.6,1.2$, and $1.8 \mathrm{mg}$ was administered. Given minimal change in blood pressure (BP), a second series of escalating PE was approved and administered. A summary of the escalating PE doses is provided in Table 1.

\subsection{Dose Escalation}

A dose-limiting toxicity (DLT) was defined as a National Cancer Institute Common Terminology Criteria for Adverse Events (NCI CTCAE)-defined adverse event (AE) Grade 4 [5], serious AE (SAE), or $\mathrm{SBP}>190 \mathrm{mmHg}$. Dose

Table 1 Phenylephrine dose levels

\begin{tabular}{lllll}
\hline Level & $\begin{array}{l}\text { No. of } \\
\text { subjects }\end{array}$ & $\begin{array}{l}\text { Phenylephrine } \\
(\mathrm{mg})\end{array}$ & Caffeine (mg) & $\begin{array}{l}\text { Cap- } \\
\text { saicin } \\
(\mathrm{mg})\end{array}$ \\
\hline 0 & 1 & 0 & 200 & 1 \\
1 & 1 & 0.6 & 200 & 1 \\
2 & 1 & 1.2 & 200 & 1 \\
3 & $6^{\mathrm{a}}$ & 1.8 & 200 & 1 \\
4 & 1 & 10 & 200 & 1 \\
5 & 1 & 20 & 200 & 1 \\
6 & 6 & 30 & 200 & 1 \\
\hline
\end{tabular}

${ }^{\mathrm{a}}$ One subject in the $1.8 \mathrm{mg} \mathrm{PE}$ cohort had a vasovagal event and did not complete pharmacokinetic sampling but was included in the safety analysis 
escalation was based on the two-step model of the phase I dose escalation schemes evaluated by Storer [6]. This dose escalation scheme did not escalate dose within an individual. Instead, a single subject was exposed to the first dose level. If the subject did not experience a DLT, the next subject was exposed to the next, higher dose. The use of a single subject per dose level continued until the highest dose level of PE within the dosing cohort was reached $(1.8 \mathrm{mg}$, then 30 $\mathrm{mg}$ ), or until a DLT was experienced. If a subject developed a DLT after the first dose but before the second dose, the second dose was not administered. The maximum tolerated dose (MTD) was defined as the PE dose (in combination with $1 \mathrm{mg}$ capsaicin and $200 \mathrm{mg}$ caffeine) that caused a DLT in fewer than $33 \%$ of the subjects treated at that dose level (viz 0-1 subjects with DLT in six subjects treated at the MTD).

\subsection{Dosing and Pharmacokinetic Visit}

There was one dosing visit for this study. Within 15 days of the in-person screening visit, subjects were admitted to the UWHealth Hospital Clinical Research Unit (CRU) where standard admission procedures occurred. Assessment of the time of the last intake of capsaicin, PE, or caffeine was documented. Subjects were asked to be fasting within $2 \mathrm{~h}$ of the drug dosing and for $1 \mathrm{~h}$ after the second dose of CPC. For the remainder of the hospital stay, a caffeine and capsaicin restricted general diet was provided.

\subsubsection{Study Drug Administration}

Subjects were asked to be in an upright position that allowed access to their mouth and subsequent blood sampling and continuous BP and heart rate (HR) monitoring. After a 15-min rest, vital signs were taken and SBP was required to be $\leq 130 \mathrm{mmHg}$ for the first dose of CPC to be administered. If $\mathrm{SBP}$ was $>130 \mathrm{mmHg}$, BP was checked again in $15 \mathrm{~min}$. If the repeat measurement was $\leq 130 \mathrm{mmHg}$, the first dose of CPC was administered. If repeat SBP was $>130 \mathrm{mmHg}$, the subject was excluded from the study.

The study nurse delivered the first dose using an oral syringe sublingually. Subjects were asked to allow the gel to reside under the tongue for $1 \mathrm{~min}$ before it could be swallowed. Sips of water were allowed after the 1-min period. Two hours later (following the 2-h blood PK sample), the sublingual dosing was repeated if SBP was $\leq 130 \mathrm{mmHg}$. If the second dose could not be administered at the 2-h time point, it was not administered at all.

Oral discomfort or pain was measured using a $0-10$ numeric pain scale (NPS), with 0 being no discomfort or pain and 10 being pain as severe as can be imagined. The NPS was recorded following the first and repeat dose, and prior to each PK blood collection. If the subject continued to have significant oral discomfort 5 min after either dose of CPC, milk and/or bread were offered after obtaining the 5-min PK samples. Subjects were queried as to the presence of gastric discomfort up to $3 \mathrm{~h}$.

\subsubsection{Pharmacokinetic Sampling}

Blood samples were collected with a syringe via the venous catheter with appropriate pre- and postsample flushing. If the indwelling venous catheter patency was lost and could not be restored, separate needle sticks for blood collection were allowed. Blood samples were collected at predose, $30 \mathrm{~s}, 1$, $2,5,15,30,45,60,90,120 \mathrm{~min}$, and 3, 4, 6, 8, 12, and $24 \mathrm{~h}$. An additional blood collection was done at the 24-h time point for $\mathrm{CBC}$ with Differential and Platelet Count, and Comprehensive Metabolic Panel.

The blood from each PK sample time was immediately transferred into one $4 \mathrm{~mL}$ collection tube containing lithium heparin (PE) and two, $2 \mathrm{~mL} \mathrm{~K}_{2}$ EDTA tubes for analysis of caffeine and capsaicin. The lithium heparin tube and one $\mathrm{K}_{2}$ EDTA tube (capsaicin sample) were immediately placed on ice or refrigerated. The second $\mathrm{K}_{2}$ EDTA tube (caffeine sample) remained at room temperature. All blood samples were centrifuged as soon as possible in a refrigerated centrifuge. The plasma from each tube was equally distributed between two polypropylene tubes, labeled and promptly stored at $-80^{\circ} \mathrm{C}$ until thawed for analysis.

\subsubsection{Cardiovascular Response}

BP via finger arterial pressure and HR via telemetry were monitored continuously using a Task Force Monitor (CNSystems Medizintechnik AG, Ganz Austria) for the first hour after each dose of study medication. In addition, we obtained automated brachial BP readings at 1, 2, 5, 10, 15, $20,30,45$, and 60 min during the $60 \mathrm{~min}$ after each dose.

\subsection{Drug Assay}

Frozen plasma samples were transported to PPD, Inc., Middleton, WI, USA, for analysis under current Good Laboratory Practices (cGLP), reflecting the May 2018 FDA Guidance for Industry-Bioanalytical Method Validation. All methods were performed using liquid chromatography-tandem mass spectrometry (LC-MS/MS). A summary of the qualification of the three assays is presented in Table 2. Stability testing demonstrated the sufficiency of sample processing and storage.

\subsection{Pharmacokinetic Analysis}

Plasma concentrations of capsaicin, PE, and caffeine were processed using non-compartmental methods using 
Table 2 Summary of validation of drug assay-interassay

\begin{tabular}{llll}
\hline & $\begin{array}{l}\text { Caffeine } \\
(25-19,000 \\
\mathrm{ng} / \mathrm{mL})\end{array}$ & $\begin{array}{l}\text { Capsaicin }(2-150 \mathrm{pg} / \\
\mathrm{mL})\end{array}$ & $\begin{array}{l}\text { Phenylephrine } \\
(10-1880 \mathrm{pg} / \\
\mathrm{mL})\end{array}$ \\
\hline Precision & $12.3 \% / 6.9 \%$ & $10.1 \% / 2.7 \%$ & $7.7 \% / 4.0 \%$ \\
Accuracy & $3.75 \% /-1.8 \%$ & $-7.24 \% /-5.1 \%$ & $-0.73 \% / 4.8 \%$ \\
\hline
\end{tabular}

Tested concentration extremes of the respective compounds are indicated within parentheses.

the PKNCA package (0.94) in R (4.0.4) within RStudio (1.4.1106) on a Dell 7410 computer operating on Windows 10. AUC was determined using the trapezoidal (linear up/ logarithmic down) method.

\section{Results}

A total of 17 subjects received the drug with no SAEs reported. As detailed in Table 3, nine subjects were in the initial low-dose PE cohort, and eight subjects received the higher doses of PE.

\subsection{Tolerability and Safety}

No SAEs were noted. Non-serious AEs were observed and included mainly oral and gastric discomfort, which were most likely related to and expected from capsaicin. Of note, oral discomfort is a desired effect for the drug as we believe it to be the trigger for increased sympathetic activity and capsaicin-induced BP elevation. Despite the reported discomfort, none of the 17 volunteers refused to hold CPC sublingually for $1 \mathrm{~min}$, swallow the drug, or take the second dose. Refusal to do any of these three things was used as a marker of intolerance of the drug.

In addition to the oral and gastric discomfort, vasovagal events thought to be the result of the frequent blood draws and intravenous catheter placement occurred in two subjects. The first subject belonged to the $1.8 \mathrm{mg}$ PE group and experienced lightheadedness, hypotension, and nausea during blood draws around 5 min after receiving the first dose. The event was consistent with a vasovagal reaction and the decision was made to stop the study given the concerns that continued blood draws were likely to exacerbate the subject's symptoms. The second subject experienced a vasovagal reaction at the sight of blood following intravenous catheter placement with no loss of consciousness. Within 5 min, the subject was back to normal and received both study doses (20 mg PE) with no further AEs. A summary of the AEs is provided in Table 4.

\subsection{Blood Levels (Capsaicin, Phenylephrine, and Caffeine)}

\subsubsection{Capsaicin Blood Concentrations}

Capsaicin blood concentrations after a $1 \mathrm{mg}$ sublingual/ oral dose ranged from $<4.00$ to $79.5 \mathrm{pg} / \mathrm{mL}$. Although the

Table 3 Subject demographics

\begin{tabular}{llllll}
\hline $\begin{array}{l}\text { Phenylephrine } \\
\text { dose (mg) }\end{array}$ & Age (years) & Sex & Weight $(\mathrm{kg})$ & Race & Ethnicity \\
\hline 0 & 19 & F & 76.5 & American Indian/ & Hispanic \\
& & & & Alaskan Native & \\
0.6 & 22 & White & Non-Hispanic \\
1.2 & 33 & 92.4 & Asian & Non-Hispanic \\
1.8 & 26 & F & 90.6 & White & Non-Hispanic \\
& 26 & F & 82.1 & Asian & Non-Hispanic \\
& 27 & F & 85.6 & White & Non-Hispanic \\
& 30 & M & 60.3 & White & Non-Hispanic \\
& 35 & F & 66.5 & White & Non-Hispanic \\
& 31 & F & 60.3 & White & Non-Hispanic \\
20 & 29 & M & 77.5 & Asian & Non-Hispanic \\
30 & 22 & M & 79.3 & White & Non-Hispanic \\
& 35 & M & 68.4 & Unknown & Hispanic \\
& 38 & F & 63.5 & White & Non-Hispanic \\
& 28 & F & 58.8 & White & Non-Hispanic \\
& 37 & F & 69.9 & White & Non-Hispanic \\
& 30 & M & 73.5 & White & Non-Hispanic \\
& 33 & F & 64.4 & White & Non-Hispanic \\
\hline & & & & &
\end{tabular}

$F$ female, $M$ male 
Table 4 Adverse effects noted

\begin{tabular}{lll}
\hline System of care & Preferred term & $\begin{array}{l}\text { No. of } \\
\text { sub- } \\
\text { jects }\end{array}$ \\
\hline $\begin{array}{l}\text { Respiratory thoracic and mediastinal } \\
\text { disorders }\end{array}$ & Throat tightness & 1 \\
$\begin{array}{ll}\text { Gastrointestinal disorders } \\
\text { Metabolism and nutrition disorders }\end{array}$ & Nausea & 2 \\
Nervous system disorders & Hypoglycemia & 1 \\
Nervous system disorders & Dizziness & 1 \\
Nervous system disorders & Headache & 1 \\
Gastrointestinal disorders & Presyncope & 2 \\
\hline
\end{tabular}

discomfort of capsaicin was noted immediately, the time to first measurable systemic concentrations was 5-15 min. A gradual increase in capsaicin concentration was noted as soon as 5 min in most subjects, reaching a peak at around 15 min with a decline over the remaining 95 min (Fig. 1). Table 5 shows the times of the first detectable and maximum concentrations of capsaisin.

\subsubsection{Phenylephrine Blood Concentrations}

PE blood concentrations did not exceed $130 \mathrm{pg} / \mathrm{mL}$ at the lower dose range $(0.6-1.8 \mathrm{mg})$. The small number of measurable concentrations limited the ability to characterize dose linearity. At the highest dose (30 mg), PE concentrations exceeded $1 \mathrm{ng} / \mathrm{mL}$ within $15 \mathrm{~min}$ and peaked at $1-2 \mathrm{ng} / \mathrm{mL}$ by 30 min with a gradual decline over 2 h (Fig. 2). The PE peak concentrations and other PK parameters are noted for the various doses in Table 6.

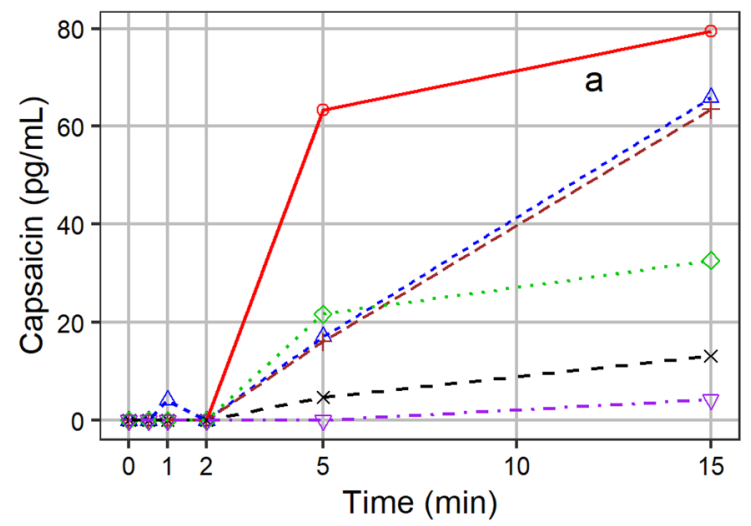

Fig. 1 Capsaicin plasma concentration. Data show plasma concentrations within the first $15 \mathrm{~min}$ after the first dose of capsaicin [1 mg] (a) and over $8 \mathrm{~h}$, comparing the concentrations after the two doses at
Table 5 Capsaicin

pharmacokinetic parameters

\begin{tabular}{ll}
\hline$N$ & 16 \\
\hline$T_{\text {first }}, \min$ & $5(0.5-30)$ \\
$T_{\max }, \min$ & $15(5-45)$ \\
$C_{\max }, \mathrm{ng} / \mathrm{L}$ & $31.3(4.22-79.5)$
\end{tabular}

Data are expressed as median (range)

$T_{1 / 2}$ could not be determined due to the inability to measure the concentrations in plasma for an adequate duration of time

$T_{\text {first }}$ time at which the first measurable concentration of drug was noted, $T_{\max }$ time at which the highest drug concentration was noted, $C_{\max }$ maximum concentration

\subsubsection{Caffeine Blood Concentrations}

Caffeine blood levels were present in some subjects at baseline, reflecting dietary caffeine intake. The blood levels were largely unchanged in the first $15 \mathrm{~min}$, suggesting the absence of sublingual absorption. There was a gradual increase after $15 \mathrm{~min}$ to $5-6 \mathrm{mcg} / \mathrm{mL}$ consistent with GI absorption. This blood level persisted for at least another $60 \mathrm{~min}$ to the end of the 2 -h period (Fig. 3). Table 7 shows the times of the first detectable and maximum concentrations of caffeine.

\subsubsection{Effect of Phenylephrine on Caffeine and Capsaicin Concentrations}

As mentioned earlier, the plasma concentrations of capsaicin were higher after the first dose than after the second dose in all subjects. Given the vasoconstritive effects of PE, the effect of PE dose on the concentration of capsaicin and caffeine was evaluated. Figure 4 shows that the concentrations

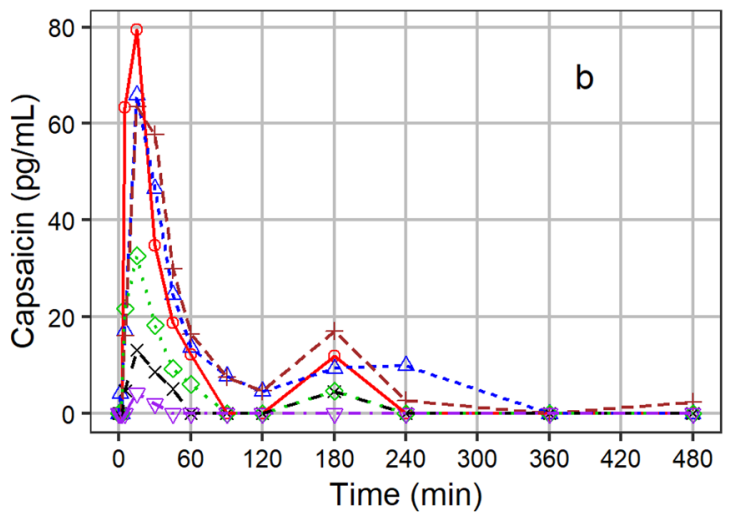

0 and $120 \mathrm{~min}$ (b). Only subjects receiving the $30 \mathrm{mg}$ phenylephrine dose are shown 

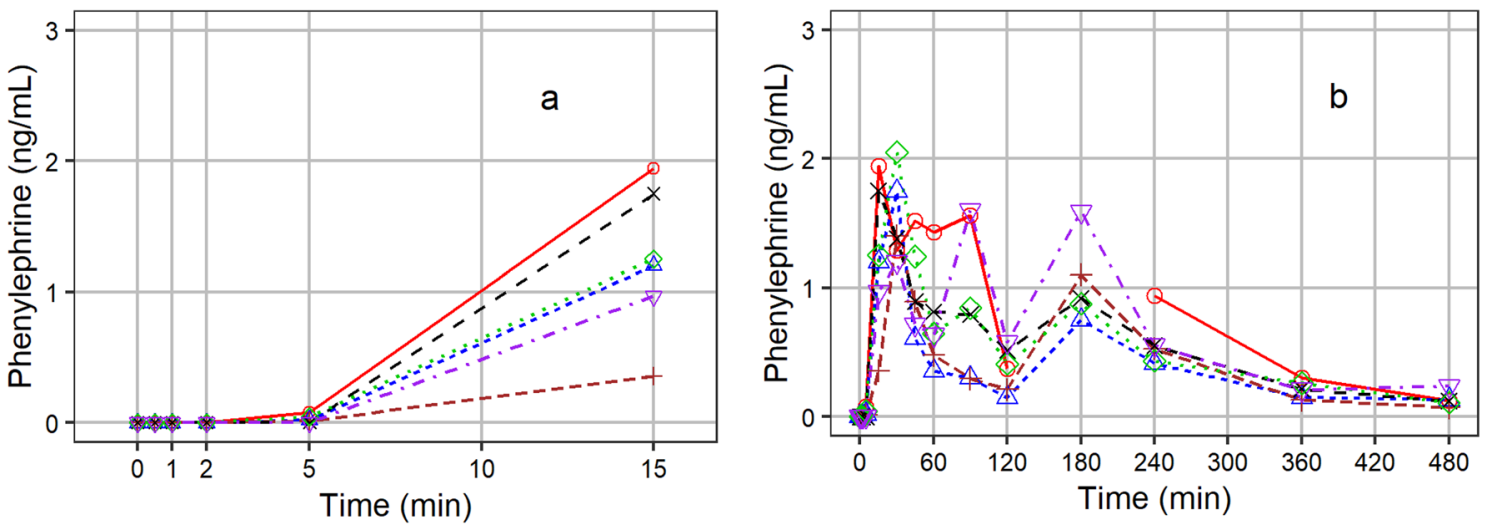

Fig. 2 Phenylephrine plasma concentration. Data are shown for patients receiving $30 \mathrm{mg}$ phenylephrine in the first $15 \mathrm{~min}$ (a) and over $8 \mathrm{~h}$, comparing the concentrations after the two doses at 0 and $120 \mathrm{~min}(\mathbf{b})$. Only subjects receiving the $30 \mathrm{mg}$ phenylephrine dose are shown

Table 6 Phenylephrine pharmacokinetic parameters

\begin{tabular}{llllllll}
\hline Dose, mg & 0.6 & 1.2 & 1.8 & 10 & 20 & 30 & All doses \\
\hline$N$ & 1 & 1 & 5 & 1 & 1 & 6 & 15 \\
$T_{\text {first }}, \min$ & 30 & 15 & $15(15-15)$ & 5 & 1 & $5(5-15)$ & $15(1-30)$ \\
$T_{\max }, \min$ & 30 & 180 & $30(15-30)$ & 45 & 180 & $30(30-180)$ & $30(15-180)$ \\
$C_{\max }, \mathrm{ng} / \mathrm{L}$ & 15.3 & 67.9 & $87.5(74.4-129)$ & 703 & 1200 & $1750(1400-3230)$ & \\
$T_{1 / 2}, \mathrm{~h}$ & $\mathrm{NA}$ & 2.49 & $1.75(0.93-2.14)$ & 2.31 & 11.1 & $4.95(2.15-7.27)$ & $2.49(0.93-11.06)$ \\
\hline
\end{tabular}

Data for multiple subjects are expressed as median (range)

Insufficient data points were available for the patient receiving the $0.6 \mathrm{mg}$ dose and one patient in the 1.8 $\mathrm{mg}$ cohort to determine the $T_{1 / 2}$ of phenylephrine. The $T_{1 / 2}$ for one subject at the $1.8 \mathrm{mg}$ dose level could not be determined

$T_{\text {first }}$ time at which the first measurable concentration of drug was noted, $T_{\max }$ time at which the highest drug concentration was noted, $C_{\max }$ maximum concentration, $T_{1 / 2}$ elimination half-life
15 min after the first dose did not significantly differ between subjects receiving the lowest and highest doses of PE.

\subsection{Cardiovascular Effects}

As noted earlier, nine and eight subjects received the lower and higher dose ranges of $\mathrm{PE}$, respectively. In the nine subjects who received the lower PE doses (0-1.8 mg), the target increase in systolic BP was not reached and PE blood levels were consistently below $0.1 \mu \mathrm{g} / \mathrm{L}$. Accordingly, higher doses of 10,20 , and $30 \mathrm{mg}$ PE were prepared and administered to an additional eight subjects with no change in the doses of caffeine and capsaicin. A significant increase in SBP was noted in all subjects in the higher PE dose cohort but still did not reach the target of $40 \mathrm{mmHg}$. PE doses higher than 30 $\mathrm{mg}$ were not investigated given the magnitude of increased $\mathrm{BP}$ and good safety outcome.

Six subjects received CPC with the highest dose of PE (capsaicin $1 \mathrm{mg}$, PE $30 \mathrm{mg}$, caffeine $200 \mathrm{mg}$ ). The median age of the cohort was 34 years and included four women.
The peak increase in SBP was at $2 \mathrm{~min}$, with an average increase of $21 \mathrm{mmHg}$ (range 15-33 $\mathrm{mmHg}$ ). The increase in BP was statistically significant for at least $15 \mathrm{~min}$ with a gradual decline over $2 \mathrm{~h}$. There was an initial increase in HR followed by a decrease to below baseline over the 2-h period (Fig. 5).

\subsection{Pain Score}

Following the first dose, the pain score (scale of 1-10) was highest at 2 min (mean 5, range 3-8) with a gradual decline over $15 \mathrm{~min}$. The mean pain scores were 3,2 , and 1 at 5,10 , and $15 \mathrm{~min}$, respectively. The pain score was 0 at $30 \mathrm{~min}$ in all subjects except for one who had a score of 1 . The same trend, except with lower numbers, was noted with the second dose, with the highest pain score noted at 2 min (mean 4, range 1-6) followed by a gradual decline to 3,1 , and 1 at 5, 10 , and 15 min respectively. As with the first dose, the pain score returned to 0 by $30 \mathrm{~min}$ in all subjects except for one who reported a score of 1 . 


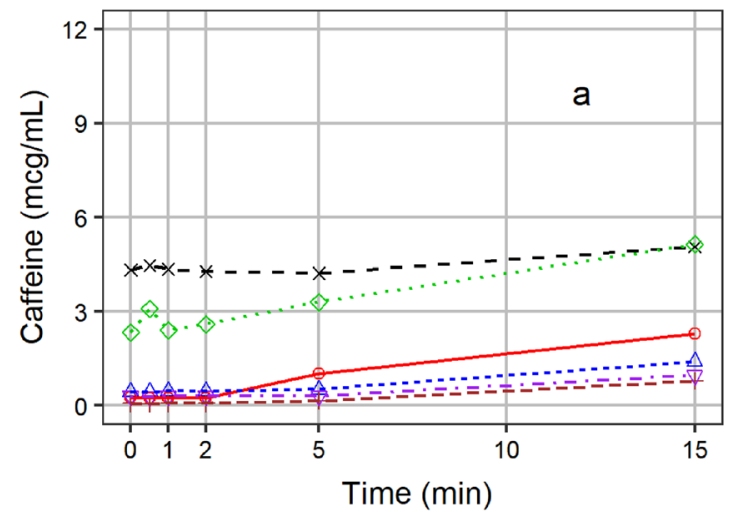

Fig. 3 Caffeine plasma concentration. Data show plasma concentrations within the first $15 \mathrm{~min}$ after the first dose of caffeine [200 mg] (a) and over $8 \mathrm{~h}$, comparing the concentrations after the two doses at

Table 7 Caffeine pharmacokinetic parameters

\begin{tabular}{lr}
\hline$N$ & 16 \\
\hline$T_{\text {first }}, \min$ & $0-5$ \\
$T_{\max }, \min$ & $60(45-120)$ \\
$C_{\max }, \mathrm{mg} / \mathrm{L}$ & $4.74(2.77-10.1)$ \\
$T_{1 / 2}, \mathrm{~h}$ & $5.34(3.76-18.8)$ \\
\hline
\end{tabular}

Data are expressed as median (range)

$T_{1 / 2}$ was determined after the second caffeine dose. Several subjects presented with non-null baseline plasma caffeine concentrations

$T_{\text {first }}$ time at which the first measurable concentration of drug was noted, $T_{\max }$ time at which the highest drug concentration was noted, $C_{\max }$ maximum concentration, $T_{1 / 2}$ elimination half-life

\section{Discussion}

The results of our phase I study suggest that the CPC drug mixture is well tolerated. We attribute the early increase in BP (0-15 min) to the oral pain associated with capsaicin, and the late increase (15-120 $\mathrm{min}$ ) to PE and caffeine. We make this statement because both PE and caffeine were barely detected in the blood during the first $15 \mathrm{~min}$, leaving only capsaicin-related oral discomfort as the cause of the early increase in BP (Fig. 6). Conversely, the later increase in BP could only be attributed to PE and caffeine because capsaicin blood levels were considered to be too low to cause a systemic effect and the oral discomfort due to capsaicin nearly subsided at $15 \mathrm{~min}$ (mean pain score of 1 at $15 \mathrm{~min}$ ). Of note, the increases in BP between 0 and $15 \mathrm{~min}$ after drug administration were similar with the lower doses of PE $(n=9)$ when compared with the higher doses $(n=8)$ (Fig. 4), suggesting once again that the early changes were due to capsaicin.

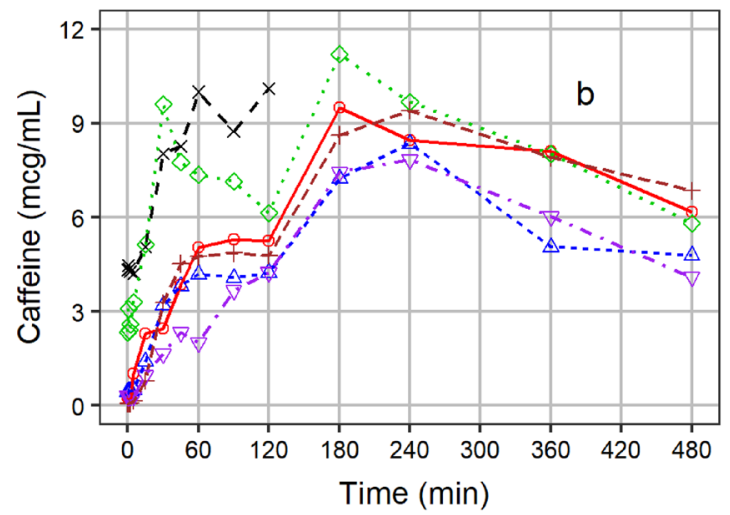

0 and $120 \mathrm{~min}$ (b). Only subjects receiving the $30 \mathrm{mg}$ phenylephrine dose are shown

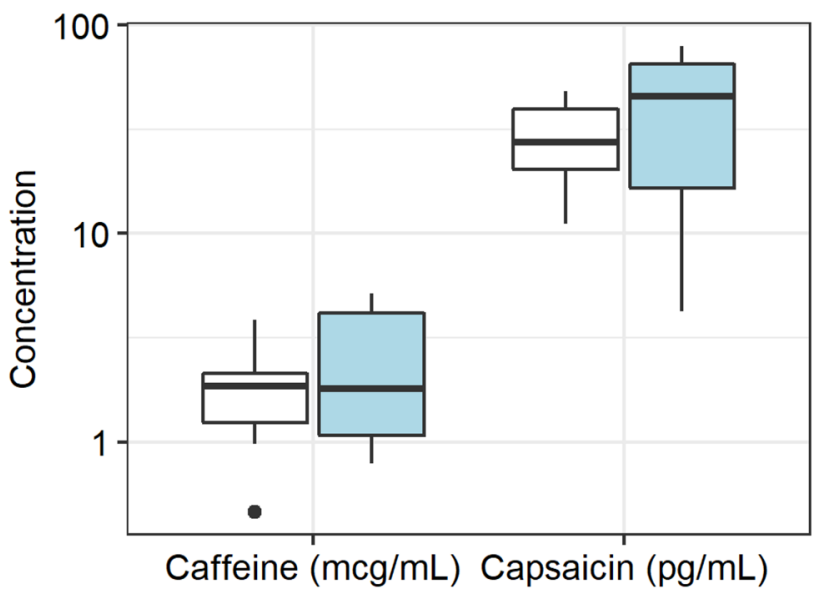

Fig. 4 Comparison of the effect of phenylephrine dose on capsaicin and caffeine concentrations $15 \mathrm{~min}$ after the first dose of the mixture. Open boxplots include subjects receiving 0-20 mg phenylephrine, and the blue boxplot includes only the six subjects receiving $30 \mathrm{mg}$ doses of phenylephrine

\subsection{Capsaicin}

The highest detected capsaicin blood level in our study following a $1 \mathrm{mg}$ oral dose was $79 \mathrm{pg} / \mathrm{mL}$ or $79 \mathrm{ng} / \mathrm{L}$, corresponding to $0.26 \mathrm{nmole} / \mathrm{L}$. The only other clinical report of capsaicin concentrations was that of Chaiyasit et al. [7], who administered oral doses of $26.6 \mathrm{mg}$ capsaicin and measured peak capsaicin concentrations of $2.5 \mu \mathrm{g} / \mathrm{L}$ or 2500 $\mathrm{ng} / \mathrm{L}$, which translates into $94 \mathrm{ng} / \mathrm{L}$ per milligram administered. This concentration is similar to our findings of $79 \mathrm{ng} / \mathrm{L}$ after the administration of $1 \mathrm{mg}$ of capsaicin.

The half maximal effective concentration $\left(\mathrm{EC}_{50}\right)$ value for capsaicin on its VR1 receptor is in the micromolar range $\left(10^{-6} \mathrm{~mole} / \mathrm{L}\right)[8,9]$. Therefore, the ratio of the highest blood level detected to $\mathrm{EC}_{50}$ is $0.26 \times 10^{-3}$. The capsaicin blood 


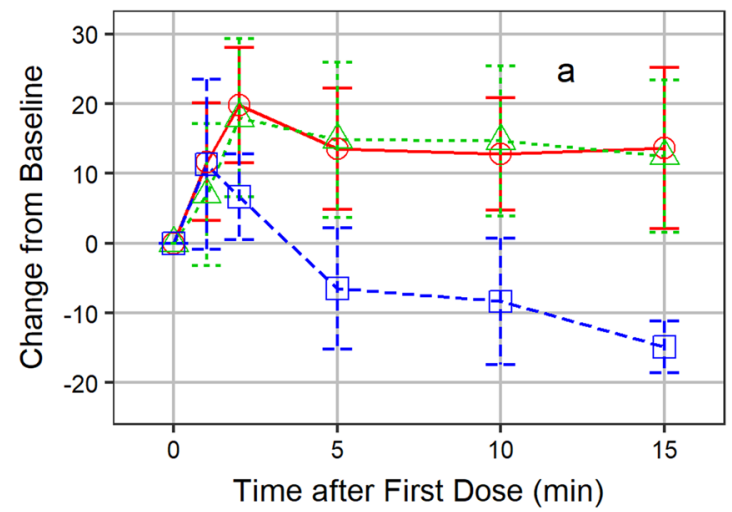

Fig. 5 Time course of cardiovascular changes. Data are shown for the first $15 \mathrm{~min}$ (a) and over $3 \mathrm{~h} \mathrm{(b).} \mathrm{Blue} \mathrm{square/dashed} \mathrm{line} \mathrm{represents}$ heart rate; red circle/solid line represents systolic blood pressure;

levels detected in this study were therefore considered to be too low to cause any effect through the systemic circulation. We hypothesize that the hemodynamic effects were due to local irritation and reflex increase in sympathetic activity. Indeed, the peak increase in SBP coincided with the highest pain score at 2 min and the decline in SBP at 15 min coincided with a mean pain score of 1 , consistent with resolution of the oral discomfort.

\subsection{Phenylephrine}

The median PE maximum concentration $\left(C_{\max }\right)$ after 30 $\mathrm{mg}$ oral doses in the current study was $1750 \mathrm{ng} / \mathrm{L}(10.5$ $\mathrm{nM}$ ), which is somewhat lower than the average of 4492 $\mathrm{ng} / \mathrm{L}$ reported by Gelotte and Zimmerman [10]. There is no obvious reason why the concentration would be lower than expected, unless the coadministration with caffeine and capsaicin decreased the rate or extent of absorption.

A PE blood concentration of $20 \mathrm{nM}$ corresponding to $3000 \mathrm{ng} / \mathrm{L}$ is associated with a mean increase of $3 \mathrm{mmHg}$ in SBP [11]. We speculate that the contribution of PE to SBP elevation was around 1-2 mmHg. Furthermore, we believe the effect was limited to the time period of $15-120 \mathrm{~min}$ when the blood levels started to exceed $1000 \mathrm{ng} / \mathrm{L}$.

\subsection{Caffeine}

The first caffeine dose of $200 \mathrm{mg}$ resulted in a median $C_{\max }$ of $4.74 \mathrm{mg} / \mathrm{L}$. This is in agreement with the $1.5 \mathrm{mg} / \mathrm{L}$ concentration reported by Perera et al. after a $100 \mathrm{mg}$ oral dose [12]. A single dose of $200-250 \mathrm{mg}$ of caffeine is associated with an increase in SBP of 3-14 mmHg within 30 min with a maximal increase at 60-120 min [13]. At a concentration of $3.7 \mathrm{mg} / \mathrm{L}$, SBP increased from $132 \pm 12$ to $133 \pm 10 \mathrm{mmHg}$ $(p<0.05)$ at $18 \mathrm{~min}$ post caffeine ingestion $(3 \mathrm{mg} / \mathrm{kg})$ [14]. In the current study, the caffeine dose was $200 \mathrm{mg}$ and the

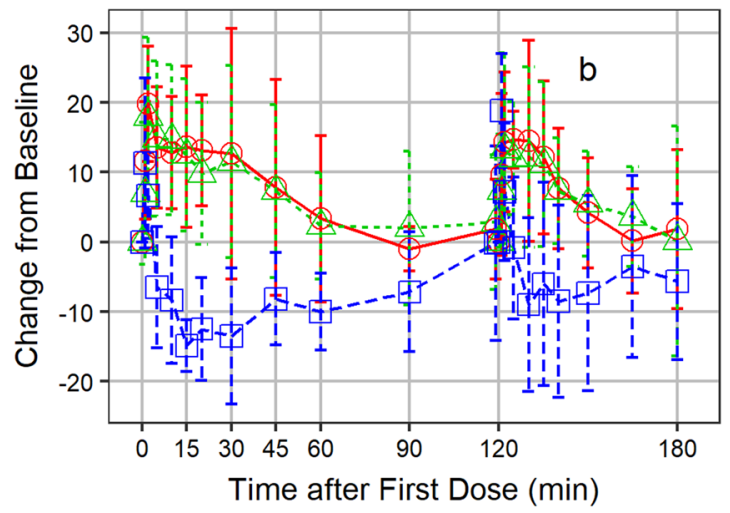

green triangle/dotted line represents diastolic blood pressure. Points and error bars indicate mean and $95 \%$ confidence interval. Only the six subjects receiving the $30 \mathrm{mg}$ phenylephrine dose are shown

blood levels were $2-6 \mu \mathrm{g} / \mathrm{mL}$ or $\mathrm{mg} / \mathrm{L}$. We speculate that the maximum contribution of caffeine to SBP elevation was approximately $1-2 \mathrm{mmHg}$. Similar to PE, we believe the effect was limited to the time period of $15-120 \mathrm{~min}$ when the blood levels started to exceed $2 \mathrm{mg} / \mathrm{L}$.

Despite the absence of significant blood levels of PE and caffeine in the first 15 min post drug administration, we believe all three drug components should continue to be part of the product for the following reasons:

1. Syncope prevention in high-risk situations: We believe the CPC product has a role in not only aborting a pending vasovagal event but also in preventing one in high-risk situations. While capsaicin plays a major role in the immediate effects ( $0-15 \mathrm{~min})$, we believe PE and caffeine play a significant role 15-120 min post drug intake. For PE, the effects are directly linked to its vasopressor properties, while for caffeine, the effects are due to its direct effects on BP and its role in blocking adenosine receptors.

With caffeine, the effects on BP are likely to be minimal in the absence of syncope; however, we hypothesize that its effects are greater at the time of pending syncope due to the endogenous release of adenosine [15] and caffeine's ability to block adenosine receptors. Indeed, the caffeine blood levels after $15 \mathrm{~min}$ are high enough to counteract the cardiovascular effects of endogenous adenosine release at the time of VVS. The affinity of caffeine for A1 and A2 adenosine receptors are 10 and $9 \mu \mathrm{M}$, respectively [16], corresponding to $1.9 \mathrm{mg} / \mathrm{L}$. The observed blood levels in our study of $2-6 \mathrm{mg} / \mathrm{L} 15-120 \mathrm{~min}$ post drug intake were at least twice that amount.

2. Effects of PE and caffeine on fatigue after a syncopal event: Up to $94 \%$ of patients experience fatigue following VVS [17], with some stating "I slept for hours as if I had run a marathon". We believe that PE and caffeine will mitigate these symptoms. 

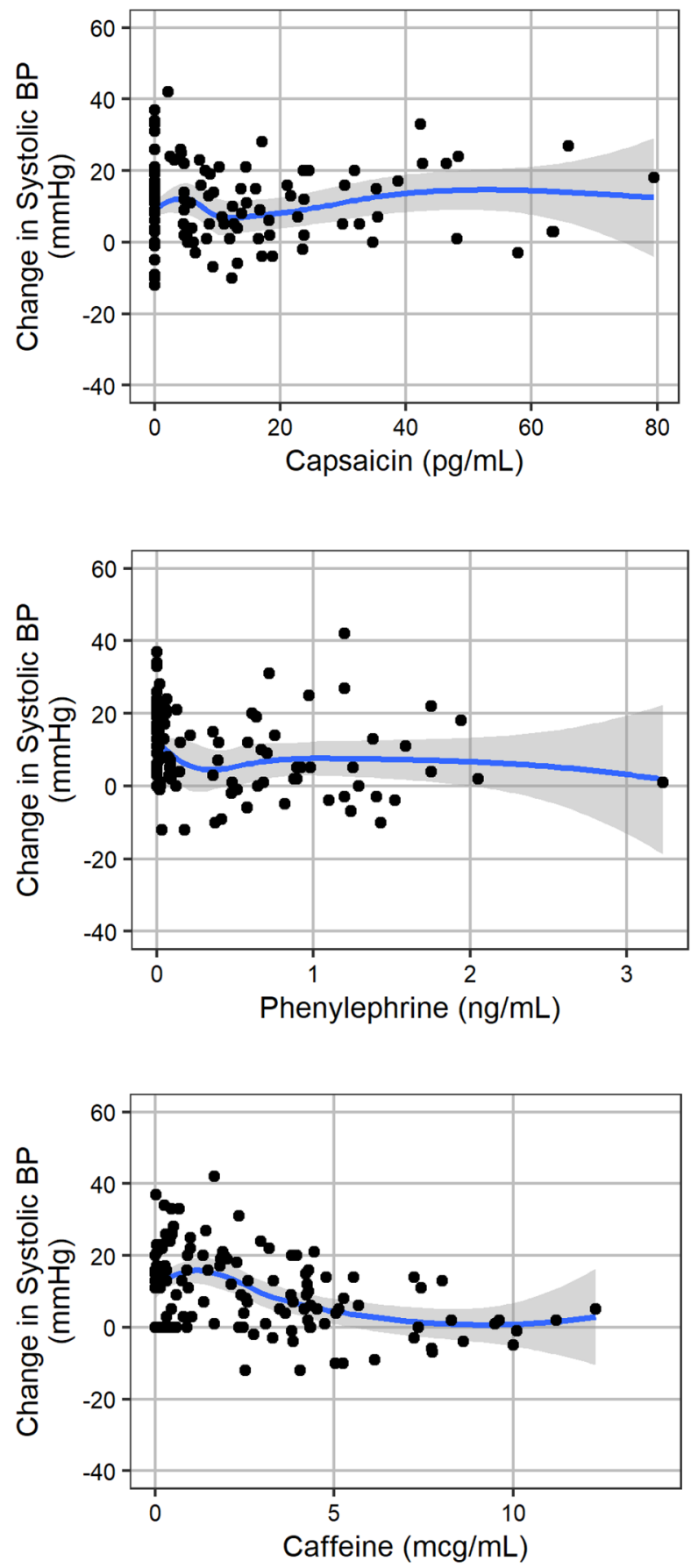

Fig. 6 Relationship of change in systolic blood pressure to drug concentrations among subjects receiving the $30 \mathrm{mg}$ phenylephrine dose, illustrating the lack of a concentration versus effect relationship. $B P$ blood pressure

\subsection{Future Studies}

Two additional studies are planned to assess the effects of CPC on VVS. In the first study, we will be testing the hypothesis that a single administration of sublingual CPC preparation during the prodromal phase aborts tilt-induced syncope or near syncope with $\mathrm{SBP} \leq 70 \mathrm{mmHg}$ in patients with a history of VVS (phase IIa trial). In the second study, we will be testing the hypothesis that a single administration of sublingual CPC preparation prevents tilt-induced hypotensive syncope or near syncope with SBP $\leq 70 \mathrm{mmHg}$ in patients with a history of VVS (phase IIb trial). Once completed, a large multicenter trial will be conducted to demonstrate the drug efficacy and safety in patients with spontaneous VVS (phase III trial).

Additional potential use of the drug include the treatment and prevention of hemodialysis-induced hypotension. There are approximately 300,000 patients receiving chronic hemodialysis in the US, with approximately 45 million sessions per year. Hypotension during hemodialysis occurs in $6-27 \%$ of patients with a $20 \%$ incidence being most cited [18]. Suggested contributors include autonomic dysfunction, particularly in diabetics [19], release of adenosine during organ ischemia [20], increased synthesis of endogenous vasodilators such as nitric oxide [21], and insufficient increase in vasoconstrictors such as vasopressin [22]. We hypothesize that administration of CPC in patients with hemodialysisinduced hypotension reduces the magnitude of BP drop and thus premature termination of hemodialysis.

Lastly, CPC may be helpful in the treatment of orthostatic hypotension. The prevalence of orthostatic hypotension is 5-30\% depending on age and type of population studied [23, 24]. While many conditions could lead to orthostatic hypotension, up to $40 \%$ of patients have no definite cause [25]. We hypothesize that CPC administration reduces the orthostatic drop in BP and thus risk of syncope and falls in patients with symptomatic orthostatic hypotension.

\section{Conclusion}

In summary, we have shown that CPC is well tolerated in healthy adults, with no serious adverse reactions. Sublingual drug administration resulted in a significant increase in BP with a peak at 2 min and gradual decline over $2 \mathrm{~h}$. The efficacy of the drug in aborting and preventing syncope awaits future studies.

\section{Declarations}

Funding Multiple discretionary funds were used to support this study (MHH).

Conflicts of interest/competing interests Paul Hutson and Cassondra Vander Ark declare that they have no conflicts of interest. Regis Guieu, Jean-Claude Deharo, Pierre Michelet, Michele Brignole, and Mohamed H. Hamdan have a pending patent application entitled 'Sublingual Formulation for Hypotension and Syncope'. 
Ethics approval This study was performed in line with the principles of the Declaration of Helsinki. Approval was granted by the University of Wisconsin Madison Human Subjects Committee (2018-1545), and performed under US IND 140732.

Consent to participate All subjects provided signed informed consent before participating in this study.

\section{Consent for publication Not applicable.}

Availability of data and material The datasets generated and/or analyzed during the current study are not publicly available due to pending patent applications but are available from the corresponding author on reasonable request.

\section{Code availability Not applicable.}

Author contributions All authors made substantial contributions to the conception or design of the work, or the acquisition, analysis, or interpretation of data. All authors either drafted the work or revised it critically for important intellectual content and approved the version to be published. All authors agree to be accountable for all aspects of the work in ensuring that questions related to the accuracy or integrity of any part of the work are appropriately investigated and resolved.

Open Access This article is licensed under a Creative Commons Attribution-NonCommercial 4.0 International License, which permits any non-commercial use, sharing, adaptation, distribution and reproduction in any medium or format, as long as you give appropriate credit to the original author(s) and the source, provide a link to the Creative Commons licence, and indicate if changes were made. The images or other third party material in this article are included in the article's Creative Commons licence, unless indicated otherwise in a credit line to the material. If material is not included in the article's Creative Commons licence and your intended use is not permitted by statutory regulation or exceeds the permitted use, you will need to obtain permission directly from the copyright holder. To view a copy of this licence, visit http://creativecommons.org/licenses/by-nc/4.0/.

\section{References}

1. Shen WK, et al. 2017 ACC/AHA/HRS Guideline for the Evaluation and Management of Patients With Syncope: Executive Summary: A Report of the American College of Cardiology/American Heart Association Task Force on Clinical Practice Guidelines and the Heart Rhythm Society. J Am Coll Cardiol. 2017;70(5):620-63. https://doi.org/10.1016/j.jacc.2017.03.002.

2. Ganzeboom KS, et al. Lifetime cumulative incidence of syncope in the general population: a study of 549 Dutch subjects aged 35-60 years. J Cardiovasc Electrophysiol. 2006;17(11):1172-6. https://doi.org/10.1111/j.1540-8167.2006.00595.x.

3. Serletis A, et al. Vasovagal syncope in medical students and their first-degree relatives. Eur Heart J. 2006;27(16):1965-70. https:// doi.org/10.1093/eurheartj/ehl147.

4. Sumner GL, et al. Recent history of vasovagal syncope in a young, referralbased population is a stronger predictor of recurrent syncope than lifetime syncope burden. J Cardiovasc Electrophysiol. 2010;21(12):137580. https://doi.org/10.1111/j.1540-8167.2010.01848.x.

5. Common Terminology Criteria for Adverse Events. https://ctep. cancer.gov/protocoldevelopment/electronic_applications/ctc.htm\# ctc_50. Accessed 4 Sept 2019.

6. Storer BE. Design and analysis of phase I clinical trials. Biometrics. 1989;45(3):925-37.
7. Chaiyasit K, Khovidhunkit W, Wittayalertpanya S. Pharmacokinetic and the effect of capsaicin in Capsicum frutescens on decreasing plasma glucose level. J Med Assoc Thai. 2009;92(1):108-13.

8. Caterina MJ, et al. The capsaicin receptor: a heat-activated ion channel in the pain pathway. Nature. 1997;389(6653):816-24. https://doi.org/10.1038/39807.

9. Yang F, et al. Structural mechanism underlying capsaicin binding and activation of the TRPV1 ion channel. Nat Chem Biol. 2015;11(7):518-24. https://doi.org/10.1038/nchembio.1835.

10. Gelotte CK, Zimmerman BA. Pharmacokinetics, safety, and cardiovascular tolerability of phenylephrine $\mathrm{HCl} 10,20$, and $30 \mathrm{mg}$ after a single oral administration in healthy volunteers. Clin Drug Investig. 2015;35(9):547-58. https://doi.org/10.1007/ s40261-015-0311-9.

11. Martinsson A, Bevegård S, Hjemdahl P. Analysis of phenylephrine in plasma: initial data about the concentration-effect relationship. Eur J Clin Pharmacol. 1986;30(4):427-31. https://doi.org/10. 1007/bf00607955.

12. Perera $\mathrm{V}$, et al. Pharmacokinetics of caffeine in plasma and saliva, and the influence of caffeine abstinence on CYP1A2 metrics. J Pharm Pharmacol. 2011;63(9):1161-8. https://doi.org/10.1111/j. 2042-7158.2011.01326.x.

13. Nurminen ML, et al. Coffee, caffeine and blood pressure: a critical review. Eur J Clin Nutr. 1999;53(11):831-9. https://doi.org/10. 1038/sj.ejcn.1600899.

14. Renda G, et al. Genetic determinants of blood pressure responses to caffeine drinking. Am J Clin Nutr. 2012;95(1):241-8. https:// doi.org/10.3945/ajcn.111.018267.

15. Deharo JC, et al. Adenosine plasma level and A2A adenosine receptor expression: correlation with laboratory tests in patients with neurally mediated syncope. Heart. 2012;98(11):855-9. https://doi.org/10.1136/heartjnl-2011-301411.

16. Jacobson KA, et al. Adenosine $\mathrm{A}(2 \mathrm{~A})$ receptor antagonists: from caffeine to selective non-xanthines. Br J Pharmacol. 2020. https:// doi.org/10.1111/bph.15103 (Epub 18 May 2020).

17. Calkins $\mathrm{H}$, et al. The value of the clinical history in the differentiation of syncope due to ventricular tachycardia, atrioventricular block, and neurocardiogenic syncope. Am J Med. 1995;98(4):365-73. https://doi.org/10.1016/s0002-9343(99) 80315-5.

18. Sands JJ, et al. Intradialytic hypotension: frequency, sources of variation and correlation with clinical outcome. Hemodial Int. 2014;18(2):415-22. https://doi.org/10.1111/hdi.12138.

19. Stojceva-Taneva $\mathrm{O}$, et al. Autonomic nervous system dysfunction and volume nonresponsive hypotension in hemodialysis patients. Am J Nephrol. 1991;11(2):123-6. https://doi.org/10.1159/00016 8287.

20. Shinzato T, et al. Role of adenosine in dialysis-induced hypotension. J Am Soc Nephrol. 1994;4(12):1987-94. https://doi.org/10. 1681/asn.V4121987.

21. Yokokawa $\mathrm{K}$, et al. Increased nitric oxide production in patients with hypotension during hemodialysis. Ann Intern Med. 1995;123(1):35-7. https://doi.org/10.7326/0003-4819-123-1199507010-00005.

22. Friess U, et al. Failure of arginine-vasopressin and other pressor hormones to increase in severe recurrent dialysis hypotension. Nephrol Dial Transplant. 1995;10(8):1421-7.

23. Low PA. Prevalence of orthostatic hypotension. Clin Auton Res. 2008;18(Suppl 1):8-13. https://doi.org/10.1007/ s10286-007-1001-3.

24. Freeman R. Clinical practice. Neurogenic orthostatic hypotension. N Engl J Med. 2008;358(6):615-24. https://doi.org/10.1056/ NEJMcp074189.

25. Robertson D, Robertson RM. Causes of chronic orthostatic hypotension. Arch Intern Med. 1994;154(14):1620-4. 